\title{
Differences in Immunological Landscape between EGFR-Mutated and Wild-Type Lung Adenocarcinoma
}

\author{
Jia-Wei Luo $\triangle{ }^{1}$ Yan-Hua Guo $\triangle{ }^{2}$ Feng-Ying Wu $\triangle{ }^{1}$ Xue-Fei Li $\oplus^{1},{ }^{1}$ Xue-Cheng Sun $\triangle{ }^{3}$ \\ Jia-Lu Wang ${ }^{4}{ }^{4}$ and Cai-Cun Zhou iD ${ }^{1}$ \\ ${ }^{1}$ Department of Medical Oncology, Shanghai Pulmonary Hospital, Thoracic Cancer Institute, Tongji University School of Medicine, \\ Shanghai 200433, China \\ ${ }^{2}$ Department of Thoracic Surgery, Tongji University Affiliated Shanghai Pulmonary Hospital, Shanghai 200433, China \\ ${ }^{3}$ Department of Pathology, Shanghai Tenth People's Hospital Affiliated to Tongji University, Shanghai 200040, China \\ ${ }^{4}$ Department of Pathology, East China Hospital Affiliated to Fudan University, Shanghai 200040, China
}

Correspondence should be addressed to Cai-Cun Zhou; caicunzhoudr@163.com

Received 15 April 2021; Accepted 9 August 2021; Published 27 August 2021

Academic Editor: laura bergantini

Copyright (C) 2021 Jia-Wei Luo et al. This is an open access article distributed under the Creative Commons Attribution License, which permits unrestricted use, distribution, and reproduction in any medium, provided the original work is properly cited.

Recent clinical trials of lung adenocarcinoma with immune checkpoint inhibitors revealed that lung adenocarcinoma patients with EGFR mutations have a poor response to immunotherapy. However, the mechanisms have not been addressed. We performed immunohistochemistry analyses of resected lung adenocarcinoma tissues with and without EGFR mutations to investigate and compare the characteristics of the tumor microenvironment (TME). We retrospectively enrolled a total of 323 lung adenocarcinoma patients (164 had EGFR mutations), and their corresponding tissue samples were analyzed by the EGFR mutation test and immunohistochemistry. We selected the markers of the immune checkpoint molecule (PD1, PD-L1, and LAG-3) and immune cell (CD3, CD4, CD8, and Foxp3) as markers of the tumor microenvironment. Our results revealed that patients had a distinct tumor microenvironment between EGFR-mutant and wild-type lung adenocarcinomas; the expression of CD3, CD4, PD-L1, and Foxp3 in EGFR-mutant tumors was significantly higher than that in wild-type tumors, while the expression of LAG3 and PD-1 showed a positive correlation with EGFR-wild-type tumors. In survival analysis, EGFR-wild-type patients had longer disease-free survival (DFS) than EGFR-mutant patients $(P=0.0065)$. Our research demonstrates significant differences in tumor microenvironment composition between EGFR-mutant and wild-type patients. Our findings provide novel evidence that contributes to understanding the mechanism underlying the poor efficacy of immune checkpoint inhibitors.

\section{Introduction}

Immunotherapy targeting programmed cell death 1 (PD1) or its ligand, PD1 ligand 1 (PD-L1), has transformed the paradigm of lung cancer treatment. Durable clinical benefit was observed in advanced lung cancer patients treated with PD1/PD-L1 inhibitors [1, 2]. Accordingly, anti-PD1/PD-L1 treatment has been approved as a second-line or first-line treatment for advanced lung adenocarcinoma [3-5]. However, despite substantial achievements in clinical care, a considerable proportion of patients does not derive benefit from anti-PD1/PD-L1 treatment. Accumulating evidence has proved that patients with EGFR mutations cannot benefit from immunotherapy [6-8]. The underlying mechanism is still unclear. The PD-L1 expression level, tumor mutation burden (TMB), and infiltrated lymphocyte have been identified as predictive markers for anti-PD1/PD-L1 immunotherapy [9]. Several studies tried to find the mechanism of immune escape in this subgroup of patients. Unfortunately, still, no report could give us a satisfying answer.

Thus, in the present study, we investigated the expression of immune checkpoint inhibitors (PD1, PD-L1, and LAG3) and infiltration of immune cells (CD3 ${ }^{+}$TILs, CD4 ${ }^{+-}$ TILs, CD ${ }^{+}$TILs, and Foxp $3^{+}$Treg) in EGFR-mutated patients and matched wild-type patients, trying to elucidate immune landscape of EGFR-mutated lung cancer. Furthermore, we collect the survival of patients, analyzed the contribution of immune factors to the survival differences. 
TABLE 1

\begin{tabular}{|c|c|c|c|c|c|}
\hline \multirow{2}{*}{ Factor } & \multirow{2}{*}{ Category } & \multicolumn{2}{|c|}{ Mutant } & \multicolumn{2}{|c|}{ Wild type } \\
\hline & & No. of patients & $\%$ & No. of patients & $\%$ \\
\hline Age (years) & Median (range) & $67.3(41-86)$ & & $64.8(35-86)$ & \\
\hline \multirow{2}{*}{ Gender } & Male & 99 & 60.4 & 114 & 71.7 \\
\hline & Female & 65 & 39.6 & 45 & 28.3 \\
\hline \multirow{2}{*}{ Smoking status } & Never smoker & 147 & 89.6 & 144 & 90.6 \\
\hline & Smoker & 17 & 10.4 & 15 & 9.5 \\
\hline \multirow{3}{*}{$\mathrm{T}$ status } & $\mathrm{T} 1$ & 80 & 48.8 & 100 & 62.9 \\
\hline & $\mathrm{T} 2$ & 79 & 48.2 & 55 & 34.6 \\
\hline & $\mathrm{T} 3$ & 5 & 3 & 4 & 2.5 \\
\hline \multirow{3}{*}{$\mathrm{N}$ status } & No & 118 & 72 & 115 & 72.3 \\
\hline & N1 & 30 & 18.3 & 31 & 19.5 \\
\hline & $\mathrm{N} 2$ & 16 & 9.8 & 13 & 8.2 \\
\hline \multirow{3}{*}{ p-stage } & I & 90 & 54.9 & 84 & 52.8 \\
\hline & II & 51 & 31.1 & 48 & 30.2 \\
\hline & IIIa & 23 & 14 & 27 & 17 \\
\hline \multirow{2}{*}{ VI } & Positive & 31 & 18.9 & 28 & 17.6 \\
\hline & Negative & 133 & 81.1 & 131 & 82.4 \\
\hline \multirow{2}{*}{ VPSI } & Positive & 101 & 61.6 & 103 & 64.8 \\
\hline & Negative & 63 & 38.4 & 56 & 35.2 \\
\hline \multirow{2}{*}{ Surgery procedure } & Lobectomy + wedge & 148 & 90.2 & 141 & 88.7 \\
\hline & Pneumonectomy & 16 & 9.8 & 18 & 11.3 \\
\hline
\end{tabular}

\section{Materials and Methods}

2.1. Patients. All patients in our study received surgical resection at Shanghai Huadong Hospital between January 2015 and December 2018. A total of 323 eligible patients were enrolled based on the following inclusion criteria: (i) they are pathologically diagnosed with lung adenocarcinoma, (ii) the pathological stage was IA to IIIA, (iii) the content of tumor tissue components can be observed on HEstained sections $\geq 20 \%$, and (iv) patient's clinical data was complete. Patient characteristics are summarized in Table 1. The median age was 68 years old (range 35-86 years) and $65.9 \%(n=213)$ were men. The follow-up was completed on May $15^{\text {th }}, 2020$. The median follow-up was 21.8 months (ranging from 4 to 47 months). The investigation was approved by the scientific review and ethics committee of Shanghai Pulmonary Hospital.

2.2. Immunohistochemistry (IHC). All specimens were examined by immunostaining tumor cells and TILs. Formalinfixed paraffin-embedded xenograft tumors $3 \mu \mathrm{m}$ thick were dewaxed in xylene, hydrated in graded alcohols, and washed with PBS. After blocking endogenous peroxidase activity with $3 \% \mathrm{H}_{2} \mathrm{O}_{2}$ aqueous solution for 10 minutes, the sections were incubated with primary antibodies overnight. After washing with PBS, they were then incubated with generaltype IgG-HRP polymer for 10 minutes, followed by $3,3^{\prime}$ -diaminobenzidine for about 3 minutes. Finally, the sections were retained with hematoxylin for 1 minute and then dehydrated in graded alcohols, cleared in xylene, and covered with coverslips [10]. Immunohistochemistry (IHC) was performed using the following antibodies: anti-human PD-L1 (clone E1L3N, Cell Signaling Technology, Danvers, MA, diluted 1:200), CD8 monoclonal antibodies (M7103, clone C8144B, DAKO, Glostrup, Denmark, diluted 1:200), CD3 monoclonal antibodies (DAKO, Santa Clara, CA, USA, diluted $1: 200$ ), CD4 monoclonal antibodies (Cell Marque, Rocklin, CA, USA, diluted 1:150), anti-Foxp3 antibody (236A/E7, ab20034, Abcam, Cambridge, USA, diluted 1:200), anti-Lag3 antibody (EPR20261, ab209236, Abcam, Cambridge, USA, diluted1:150), and anti-PD1 antibody (NAT105, ab52587, Abcam, Cambridge, USA, diluted $1: 200)$. PD-L1 expression was evaluated based on the intensity and proportion of tumor cells displaying either in membranous or in cytoplasmic staining by two independent pathologist. Lymphocytes with the cytoplasmic expression of CD8 infiltrating within the tumor region, either in the central or in the marginal tumor region, were defined as CD ${ }^{+}$TILs.

2.3. IHC Scoring Strategy. The markers were scored in four categories: no staining (0), weak staining (1, light-brown membrane staining, visible only with high magnification), intermediate staining (2, between 1 and 3 ), and strong staining (3, visible with low magnification, dark-brown linear membrane staining); according to the results, they are 

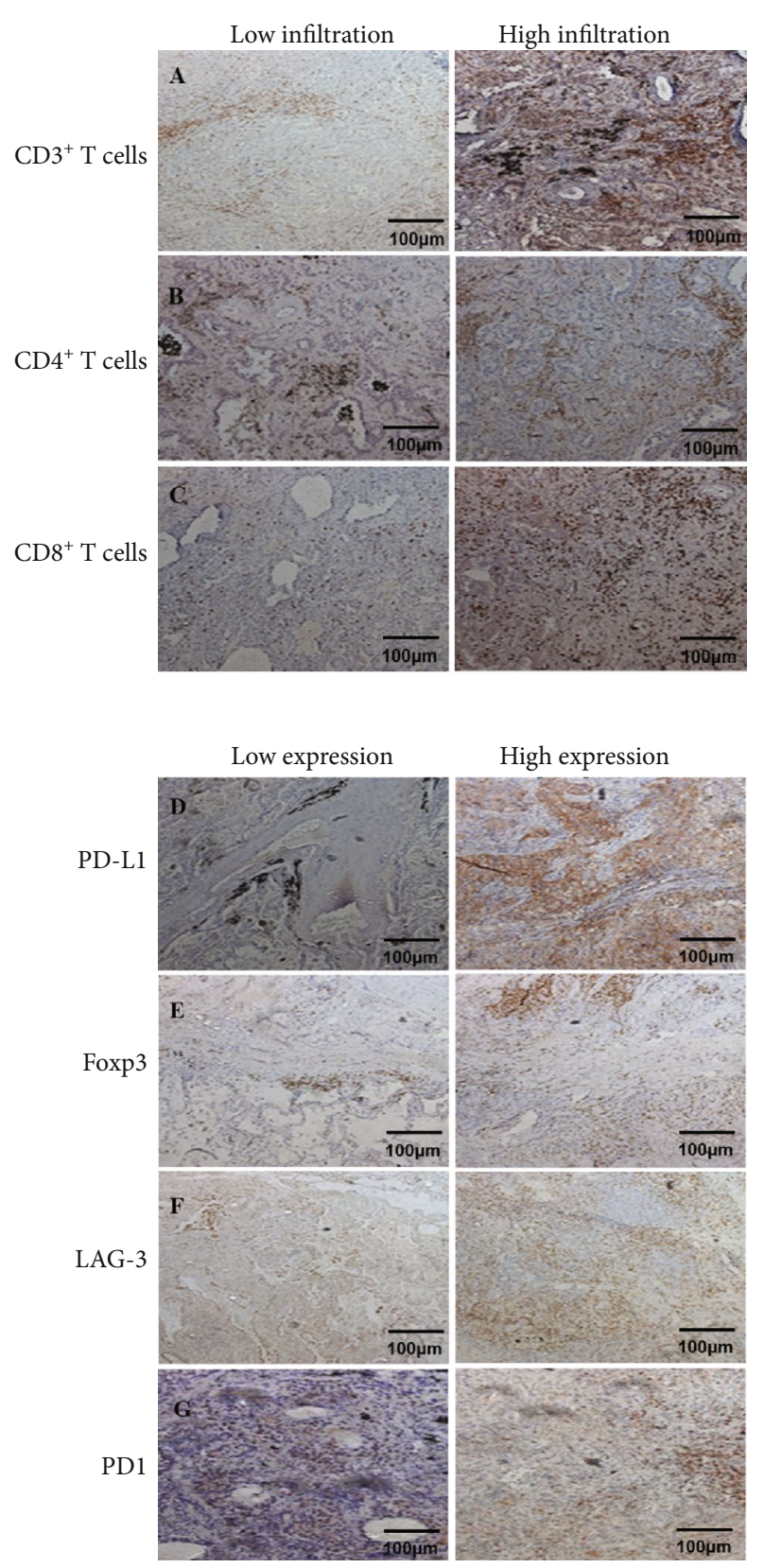

Figure 1: Schematic diagram of immunohistochemical staining of markers. (a) $\mathrm{CD}^{+} \mathrm{T}$ cell staining; (a), 1: low infiltration of $\mathrm{CD}^{+}$ $\mathrm{T}$ cells; (a), 2: high infiltration of $\mathrm{CD}^{+} \mathrm{T}$ cells; (b) $\mathrm{CD} 4^{+} \mathrm{T}$ cell staining; (b), 1: low infiltration of $\mathrm{CD}^{+} \mathrm{T}$ cells; (b), 2: high infiltration of $\mathrm{CD}^{+} \mathrm{T}$ cells; (c) $\mathrm{CD}^{+} \mathrm{T}$ cell staining; (c), 1: low infiltration of $\mathrm{CD}^{+} \mathrm{T}$ cells; (c), 2: high infiltration of $\mathrm{CD}^{+} \mathrm{T}$ cells; (d) PD-L1 staining; (d), 1: low expression of PD-L1; (d), 2: high expression of PD-L1; (e) Foxp3 staining; (e), 1: low expression of Foxp3; (e), 2: high expression of Foxp3; (f) LAG-3 staining; (f), 1: low expression of LAG-3; (f), 2: high expression of LAG-3; (g) PD1 staining; (g), 1: low expression of PD1; (g), 2: high expression of PD1.

divided into high (score 2-3) and low (score 0-1) categories by two independent pathologists. As for PD-L1, a threshold of at least $5 \%$ of cells with membranous staining to define positivity was used.

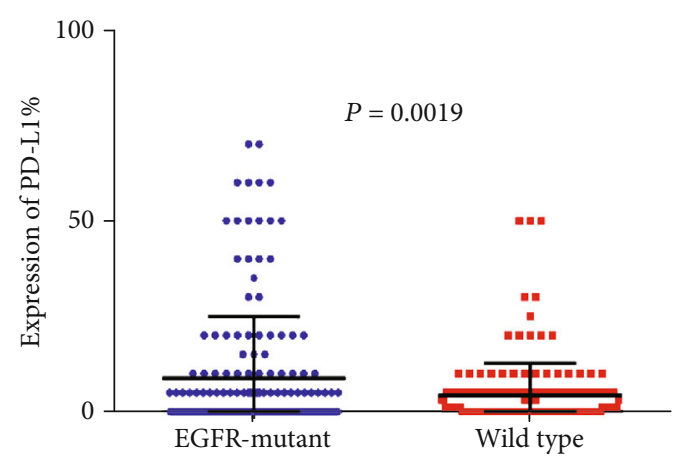

FIgURE 2: Comparison of PD-L1 expression between EGFR-mutant and wild-type lung adenocarcinoma tumor microenvironment.

2.4. EGFR Mutation Test. The EGFR status of all specimens mentioned before was carried out using amplification refractory mutation system-PCR (ARMS-PCR) technology on a Bio-Rad CFX96 machine (Bio-Rad, American), which is fully evaluated on histological tissue. The ADx EGFR Mutations Detection Kit (Amoy Diagnostics, China) was subjected to this procedure. There are 29 known mutations in exons 18-21 of EGFR, including G719X in exon 18, deletion in exon 19, S768I and T90M in exon 20, and L861Q in exon 21.

2.5. Statistical Analysis. The comparison of categorical variables and the association between various markers and clinicopathologic features were confirmed by the chisquare test or Fisher exact test, and the nonparametric test was used to evaluate the differences in continuous variables. The disease-free survival (DFS) was defined as the time from random assignment to the time of the first event (progression, death) [11]. Patients with no events were censored at the date of their last follow-up. The survival curve plots were completed by using the Kaplan-Meier method and compared by the log-rank test. Univariate analysis was used to identify the factors associated with DFS. All significant variables in univariate analysis were screened and enter the multivariate Cox regression analysis. All analyses were performed by IBM SPSS Statistics V 17.0 (IBM), and the $P$ value of 0.05 was considered statistically significant.

\section{Results}

3.1. Clinicopathological Characteristics. The characteristics of patients are summarized in Table 1. A total of 323 earlystage lung adenocarcinoma patients (IA to IIIA) who received surgical treatment were included. Tissues from resected tumors were obtained. The median age at diagnosis was 68 years (ranging from 35 to 86$)$. 213 patients $(65.9 \%)$ were male and $32(9.9 \%)$ patients had a history of smoking. Pathological TNM stages were I for 183 patients (56.7\%), II for 99 patients $(30.7 \%)$, and III for 50 patients (15.5\%). 164 patients $(50.8 \%)$ had EGFR mutations and 159 patients (49.2\%) without EGFR mutation. 


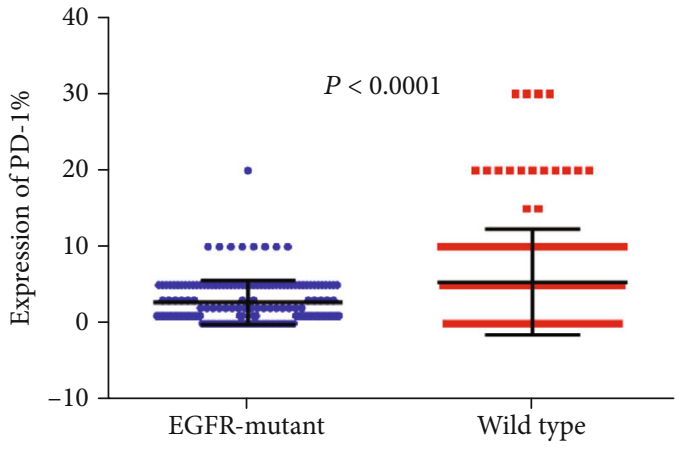

FIGURE 3: Comparison of PD-1 expression between EGFR-mutant and wild-type lung adenocarcinoma tumor microenvironment.

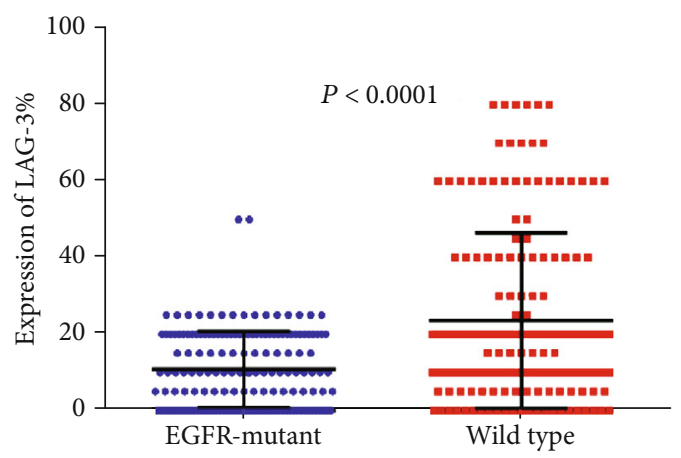

FIGURE 4: Comparison of LAG-3 expression between EGFR-mutant and wild-type lung adenocarcinoma tumor microenvironment.

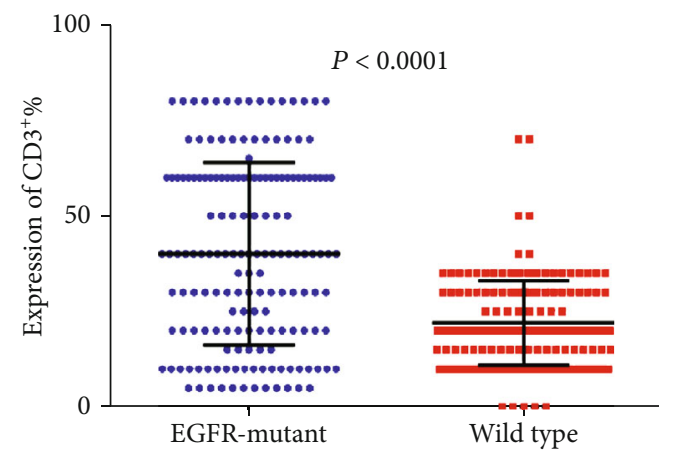

FIgURE 5: Comparison of $\mathrm{CD}^{+} \mathrm{T}$ cell infiltration between EGFRmutant and wild-type lung adenocarcinoma tumor microenvironment.

3.2. Expression of the Immune Checkpoint Molecule in EGFR-Mutant vs Wild-Type Lung Cancer Patients. To elucidate the expression of the immune checkpoint molecule in EGFR-mutated patients, we detect the expression of PD-L1, PD1, and LAG3 in all the samples (Figure 1). We found that PD-L1 expression is significantly higher in EGFR-mutated patients than in wild-type patients $(P=0.0019$; Figure 2$)$. However, the expression of PD-1 and LAG3 was lower in EGFR-mutated patients when compared with wild-type patients $(P<0.0001$ vs $P<0.0001$ separately; Figures 3 and 4$)$.

3.3. Immune Cell Infiltration in EGFR-Mutated and WildType Lung Cancer Patients. Tumor-infiltrating lymphocytes

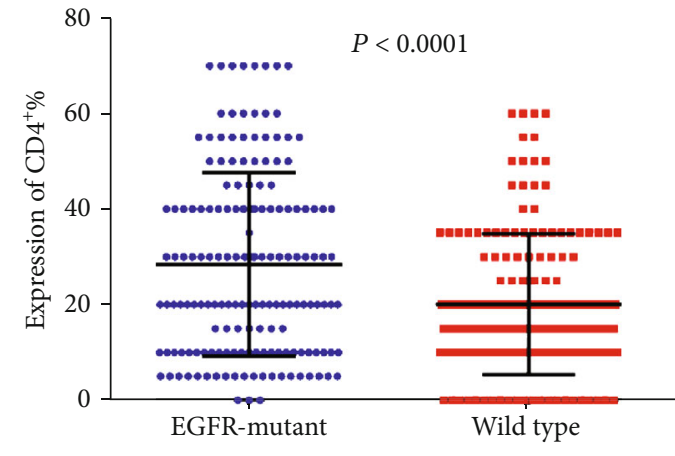

FIgURE 6: Comparison of $\mathrm{CD} 4^{+} \mathrm{T}$ cell infiltration between EGFRmutant and wild-type lung adenocarcinoma tumor microenvironment.

(TILs) are an important predictive biomarker for anti-PD1 immunotherapy. Thus, we evaluated the infiltration of $\mathrm{CD}^{+}{ }^{+} \mathrm{T}$ cell, $\mathrm{CD}^{+} \mathrm{T}$ cell, $\mathrm{CD} 8^{+} \mathrm{T}$ cell, and Foxp $3^{+} \mathrm{T}$ cell in EGFR-mutated and wild-type patients separately. We observed that the number of $\mathrm{CD}^{+}$TILs and CD4 $4^{+}$TILs is significantly higher in EGFR-mutant tumors than in wildtype tumors $(P<0.0001$ and $P<0.0001$ separately; Figures 5 and 6). However, no significant differences were observed for the infiltration of $\mathrm{CD}^{+}$TILs $(P=0.8970$; Figure 7). Notably, the amounts of Foxp $3^{+}$TILs in the EGFR-mutant tumors were dramatically higher when compared with wild-type tumors $(P<0.0001$; Figure 8$)$.

3.4. The Outcome of Patients according to EGFR Mutation and the Immune Microenvironment. The gene mutation status and tumor microenvironment might be associated with the outcome of patients. We investigate the DFS of patients with different subgroups. As shown in the Kaplan-Meier curve, DFS was longer in the wild-type patients than in the $E G F R$-mutant patients $(P=0.0065$; Figure 9$)$. Moreover, we divided patients into 7 subgroups according to the immune microenvironment: $\mathrm{PD}-\mathrm{L}^{+} / \mathrm{PD}-\mathrm{L}^{-}, \mathrm{CD} 3^{\text {high }} / \mathrm{C}-$ $\mathrm{D} 3^{\text {low }}, \mathrm{CD} 4^{\text {high }} / \mathrm{CD} 4^{\text {low }}, \mathrm{CD} 8^{\text {high }} / \mathrm{CD} 8^{\text {low }}$, Foxp $3^{\text {high }} /$ Fox$\mathrm{p} 3^{\text {low }}, \mathrm{LAG} 3^{\text {high }} / \mathrm{LAG} 3^{\text {low }}$, and PD1 $1^{\text {high }} / \mathrm{PD} 1^{\text {low }}$.

Among the whole cohort, univariate and multivariate analyses were undertaken to find factors that contribute to DFS in EGFR-mutated and wild-type patients separately (Table 2). We found that age $\geq 66$ years (age $<66$ years; $\mathrm{HR}=1.169 ; 95 \% \mathrm{CI}, 1.112-1.877 ; P=0.009)$ and Foxp ${ }^{\text {low }}$ TILs (Foxp ${ }^{\text {high }}$ TILs; HR $=0.711 ; 95 \%$ CI, 0.381-1.101; $P=$ 0.017 ) were independent prognostic factors for DFS in EGFR-mutant lung adenocarcinoma.

\section{Discussion}

The TME refers to the cellular environment in which tumors or cancer stem cells exist. Cancer stem cells are cells in a tumor with the abilities to self-renew and drive tumorigenesis [12]. The TME encompasses the surrounding immune cells, blood vessels, extracellular matrix (ECM), fibroblasts, lymphocytes, bone marrow-derived inflammatory cells, and signaling molecules $[13,14]$. Interactions between malignant and nonmalignant cells create a TME that affects cancer 


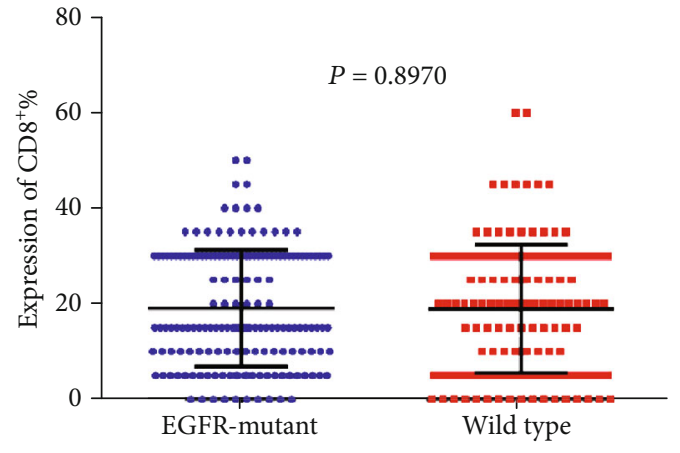

FIgURE 7: Comparison of $\mathrm{CD}^{+} \mathrm{T}$ cell infiltration between EGFRmutant and wild-type lung adenocarcinoma tumor microenvironment,

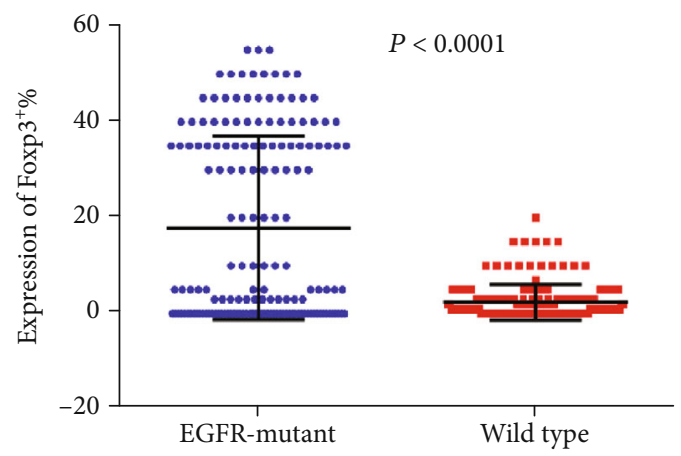

FIGURE 8: Comparison of Foxp $3^{+} \mathrm{T}$ cell infiltration between EGFRmutant and wild-type lung adenocarcinoma tumor microenvironment.

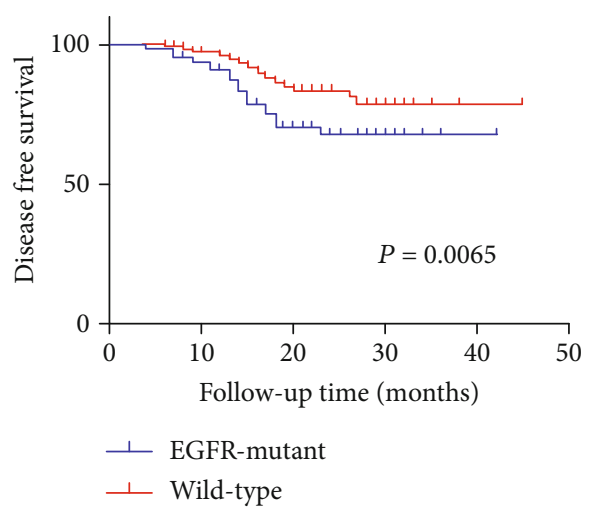

FIGURE 9: Comparison of postoperative DFS between EGFRmutant and wild-type patients.

development and progression $[15,16]$. The nonmalignant cells in the TME often play a protumorigenic function at all phases of carcinogenesis by stimulating uncontrolled cell proliferation [17]. It has been reported that cancer development and progression are influenced by components of the TME and controlled by the host immune system [18]. Therefore, TME components and immune system biomarkers are important for cancer detection and evaluations of prognoses and treatment response [19]. The examination of the immune TME has a critical prognostic value and can supplement histopathological and molecular biomarkers with regard to the evaluation of patient responses to treatment. It is of great significance to further study the molecular mechanisms affecting TME.

Mechanistically, it has been well documented that PD-L1 expressed on tumor cells would facilitate tumor immune tolerance and evasion of the host by interacting with its receptor PD-1 on T cells and leading to T cell inactivation or exhaustion in the tumor microenvironment [20]. PD-L1 has been traditionally considered as a negative costimulatory molecule promoted constitutively by oncogenic driver mutations and indicates defective adaptive immune response in many solid tumors [21]. Following this rationale, the overexpression of PD-L1 by tumor cells behooves to correlate with poorer prognosis [22]. However, according to our findings, EGFR-mutant tumors have higher expression of PD-L1 than tumors without EGFR mutations. And PD-1 expression levels appear to be negative correlated. The results contradict some previous studies [23]. This result may be due to the small sample size of this study, which is insufficient to explain the expression correlation between them. Actually, the diversity remains in the outcome obtained from different studies investigating whether PD-L1 could be recognized as an effective biomarker of prognosis. Maybe, high PD-L1 expression in EGFR-mutant patients may be only a result of the oncogene drive, rather than the main cause of tumor immune escape [24].

The immune infiltrate, in lung cancers as well as in other malignancies, has been shown to comprise adaptive and innate immune cells [25]. Here, we evaluated the infiltration of lung adenocarcinoma $\mathrm{CD}^{+}{ }^{+} \mathrm{T}$ cell, $\mathrm{CD} 4^{+} \mathrm{T}$ cell, $\mathrm{CD} 8^{+} \mathrm{T}$ cell, Foxp $3^{+} \mathrm{T}$ cell, and their matched normal tissues. Our study showed that tumor-infiltrating Treg cells are different from normal tissue-infiltrating Tregs, suggesting that the tumor microenvironment influences specific gene expression in Treg cells, and further support the view that Treg cells from different tissues are instructed by environmental factors to display different gene expression profiles. These data could help a better understanding of the Treg functional role at tumor sites and pave the way to the identification of therapeutic targets for more specific and safer modulation of Treg cells in cancer therapy.

We took the univariate and multivariate analyses to find factors that contribute to DFS in lung adenocarcinoma. Increased Treg frequency has been associated with poor outcomes in cancer patients $[26,27]$. Our results showed that high infiltration of Tregs in our cohorts was positively associated with poor prognosis of patients. The frequency of Tregs in tumors with EGFR mutations was significantly higher than that in wild-type tumors. The regulatory $\mathrm{T}$ cells (Tregs) are one of the most important inhibitory components in the TME [28]; Tregs influence the tumor microenvironment during the progression of lung cancers [29]. Murine models of lung adenocarcinoma have demonstrated that Tregs may inhibit CD8 $\mathrm{T}$ cell-mediated antitumor immunity, with the depletion of Tregs resulting in tumor cell death and elevated levels of granzyme A, granzyme B, perforin, and IFN- $\gamma$ in infiltrating CD8 T cells at early stages of tumorigenesis [30]. Further, the development of SCLC 
TABLE 2

\begin{tabular}{|c|c|c|c|c|c|c|c|c|c|c|}
\hline \multirow[b]{2}{*}{ Clinicopathologic features } & \multirow[b]{2}{*}{ HR } & \multicolumn{5}{|c|}{ EGFR mutant } & \multicolumn{4}{|c|}{ Wild type } \\
\hline & & $\begin{array}{c}\text { Univariate } \\
95 \% \text { CI }\end{array}$ & $\begin{array}{c}P \\
\text { value }\end{array}$ & HR & $\begin{array}{c}\text { Multivariate } \\
95 \% \text { CI }\end{array}$ & $\begin{array}{c}P \\
\text { value }\end{array}$ & $\begin{array}{l}\text { Univariate } \\
\text { HR95\% CI }\end{array}$ & $\begin{array}{c}P \\
\text { value }\end{array}$ & HR & $\begin{array}{c}\text { Multivariate } \\
95 \% \text { CIP } \\
\text { value }\end{array}$ \\
\hline Age $\geq 66$ vs $<66$ & 1.305 & $\begin{array}{l}0.988 \text { to } \\
2.987\end{array}$ & 0.030 & 1.169 & $\begin{array}{l}1.112 \text { to } \\
1.877\end{array}$ & 0.009 & $\begin{array}{l}1.1430 .329 \\
\text { to } 2.619\end{array}$ & 0.811 & & \\
\hline Male vs female & 0.927 & $\begin{array}{l}0.539 \text { to } \\
2.101\end{array}$ & 0.893 & & & & $\begin{array}{l}1.6240 .510 \\
\text { to } 4.364\end{array}$ & 0.351 & & \\
\hline Smoking vs no smoking & 1.323 & $\begin{array}{l}0.321 \text { to } \\
3.257\end{array}$ & 0.610 & & & & $\begin{array}{l}1.1120 .211 \\
\text { to } 3.401\end{array}$ & 0.941 & & \\
\hline T stage: $\mathrm{T} 1$ vs $\mathrm{T} 2-3$ & 0.391 & $\begin{array}{c}0.145 \text { to } \\
0.840\end{array}$ & 0.021 & 0.531 & $\begin{array}{l}0.126 \text { to } \\
1.216\end{array}$ & 0.323 & $\begin{array}{l}0.7180 .208 \\
\text { to } 1.204\end{array}$ & 0.513 & & \\
\hline $\mathrm{N}$ stage: $\mathrm{N} 0$ vs $\mathrm{N} 1-2$ & 0.801 & $\begin{array}{l}0.354 \text { to } \\
2.135\end{array}$ & 0.611 & & & & $\begin{array}{l}0.1640 .043 \\
\text { to } 0.491\end{array}$ & 0.001 & 0.312 & $\begin{array}{l}0.089 \text { to } \\
1.1210 .069\end{array}$ \\
\hline Pathological stage: I vs II-IIIA & 0.331 & $\begin{array}{c}0.164 \text { to } \\
0.805\end{array}$ & 0.022 & 0.421 & $\begin{array}{l}0.170 \text { to } \\
1.214\end{array}$ & 0.132 & $\begin{array}{l}0.2270 .079 \\
\text { to } 0.799\end{array}$ & 0.014 & 0.316 & $\begin{array}{c}0.075 \text { to } \\
2.1990 .314\end{array}$ \\
\hline $\begin{array}{l}\text { Vascular infiltration: positive vs } \\
\text { negative }\end{array}$ & 3.788 & $\begin{array}{l}1.573 \text { to } \\
15.201\end{array}$ & 0.001 & 0.601 & $\begin{array}{l}0.283 \text { to } \\
1.729\end{array}$ & 0.301 & $\begin{array}{l}3.2011 .609 \\
\text { to } 10.821\end{array}$ & 0.004 & 0.716 & $\begin{array}{l}0.266 \text { to } \\
2.2150 .715\end{array}$ \\
\hline Pleural infiltration: positive vs negative & 3.804 & $\begin{array}{l}1.277 \text { to } \\
7.112\end{array}$ & 0.016 & 0.721 & $\begin{array}{l}0.219 \text { to } \\
2.228\end{array}$ & 0.739 & $\begin{array}{l}0.8860 .367 \\
\text { to } 2.112\end{array}$ & 0.801 & & \\
\hline $\begin{array}{l}\text { Surgical method: wedge resection + } \\
\text { lobectomy vs total resection }\end{array}$ & 0.704 & $\begin{array}{l}0.195 \text { to } \\
2.140\end{array}$ & 0.622 & & & & $\begin{array}{l}2.7210 .518 \\
\text { to } 6.412\end{array}$ & 0.301 & & \\
\hline CD3: low vs high & 1.311 & $\begin{array}{l}0.538 \text { to } \\
2.106\end{array}$ & 0.434 & & & & $\begin{array}{l}0.7320 .236 \\
\text { to } 2.112\end{array}$ & 0.615 & & \\
\hline CD4: low vs high & 1.201 & $\begin{array}{l}0.501 \text { to } \\
2.135\end{array}$ & 0.501 & & & & $\begin{array}{l}1.1330 .368 \\
\text { to } 2.160\end{array}$ & 0.829 & & \\
\hline CD8: low vs high & 0.820 & $\begin{array}{c}0.417 \text { to } \\
2.007\end{array}$ & 0.277 & & & & $\begin{array}{l}1.2440 .442 \\
\text { to } 3.223\end{array}$ & 0.544 & & \\
\hline Foxp3: low vs high & 0.713 & $\begin{array}{c}0.289 \text { to } \\
0.912\end{array}$ & 0.022 & 0.711 & $\begin{array}{c}0.381 \text { to } \\
1.101\end{array}$ & 0.017 & $\begin{array}{l}2.1360 .711 \\
\text { to } 4.111\end{array}$ & 0.201 & & \\
\hline LAG3: low vs high & 2.014 & $\begin{array}{c}0.834 \text { to } \\
4.324\end{array}$ & 0.112 & & & & $\begin{array}{l}4.2421 .609 \\
\text { to } 6.757\end{array}$ & 0.126 & & \\
\hline PD-L1: positive vs negative & 1.114 & $\begin{array}{l}0.492 \text { to } \\
2.303\end{array}$ & 0.791 & & & & $\begin{array}{l}0.6500 .213 \\
\text { to } 2.406\end{array}$ & 0.611 & & \\
\hline PD-1: low vs high & 0.335 & $\begin{array}{c}0.654 \text { to } \\
1.142\end{array}$ & 0.031 & 0.402 & $\begin{array}{c}0.413 \text { to } \\
1.212\end{array}$ & 0.102 & $\begin{array}{c}0.6990 .211 \\
\text { to } 2.112\end{array}$ & 0.664 & & \\
\hline
\end{tabular}

influences immunosuppressive activities of Tregs, where SCLC cell lines were reported to induce Treg generation from CD4 $\mathrm{T}$ cells through the production of IL-15 [31]. A clinical study of NSCLC observed that Treg levels in peripheral blood increased with the stage and were highest in patients with metastatic tumors [32]. Emerging evidence suggests that Tregs promote metastasis and metastatic tumor focus development [33]. Other factors are at play and the molecular mechanisms underlying Treg recruitment and their immunosuppressive functions in the lung tumor microenvironment require further study to improve patient therapy and outcomes.

PD-L1 expression on tumor cells could be attributed to IFN- $\gamma$ production by TILs, which is in association with powerful antitumor immunity and favorable prognosis in theory [17]. Prognostically, a high proportion of Foxp3 lymphocytes in SCLC lung tumor biopsies correlates with poor survival [18]. Another study in NSCLC identified that elevated levels of intertumoral Foxp3 lymphocytes were associated with reduced recurrence-free survival [19]. In the study, we found that patients with age $\geq 66$ years and Foxp ${ }^{\text {low }}$ TILs were independent prognostic factors for DFS in EGFRmutant lung adenocarcinoma. This finding may provide a novel option for prognosis prediction of lung adenocarcinoma patients.

It must be acknowledged that our research has several limitations. First, the EGFR wild-type group may have been heterogeneous, leading to the possible inclusion of patients with other mutations (KRAS, TP53, ROS1, STK11, etc.), which may influence PD-L1 expression and $\mathrm{CD}^{+} \mathrm{T}$ cell infiltration. Second, all the patients were in the early stage and the data of OS was not available. Third, there is a lack of in-depth analysis of the immune landscape, including proliferation $\mathrm{T}$ cells, effector $\mathrm{T}$ cell, naive $\mathrm{T}$ cells, $\mathrm{NK}, \mathrm{DC}$, $\mathrm{B}$ cells, and MDSC. Therefore, we intend to further analyze subsequent single-cell sequencing.

In summary, our study is the first to clarify the detailed differences in immunological landscape in lung 
adenocarcinoma with and without EGFR mutation. Our findings offer novel evidence that EGFR-mutant tumors have a higher infiltration of Tregs compared with wild-type tumors, which could be the main cause of impaired response to PD-1 pathway blockade in EGFR-driven lung adenocarcinoma. Besides, our research suggests that Tregs could be regarded as a promising target for treatment of lung adenocarcinoma in the future.

\section{Data Availability}

No data were used to support this study.

\section{Conflicts of Interest}

The authors have declared no conflicts of interest.

\section{Authors' Contributions}

Jia-Wei Luo, Yan-Hua Guo, and Feng-Ying Wu contributed equally to this work.

\section{Acknowledgments}

This study was supported in part by grants from the National Natural Science Foundation of China (no. 8187100600).

\section{References}

[1] S. Gettinger, L. Horn, D. Jackman et al., "Five-year follow-up of nivolumab in previously treated advanced non-small-cell lung cancer: results from the CA209-003 study," Journal of Clinical Oncology, vol. 36, no. 17, pp. 1675-1684, 2018.

[2] O. Hamid, C. Robert, A. Daud et al., "Five-year survival outcomes for patients with advanced melanoma treated with pembrolizumab in KEYNOTE-001," Annals of Oncology, vol. 30, no. 4, pp. 582-588, 2019.

[3] H. Borghaei, L. Paz-Ares, L. Horn et al., "Nivolumab versus docetaxel in advanced nonsquamous non-small-cell lung cancer," The New England Journal of Medicine, vol. 373, no. 17, pp. 1627-1639, 2015.

[4] J. Brahmer, K. L. Reckamp, P. Baas et al., "Nivolumab versus docetaxel in advanced squamous-cell non-small-cell lung cancer," The New England Journal of Medicine, vol. 373, no. 2, pp. 123-135, 2015.

[5] R. S. Herbst, P. Baas, D. W. Kim et al., "Pembrolizumab versus docetaxel for previously treated, PD-L1-positive, advanced non-small-cell lung cancer (KEYNOTE-010): a randomised controlled trial," The Lancet, vol. 387 , no. 10027 , pp. $1540-$ 1550, 2016.

[6] J. F. Gainor, A. T. Shaw, L. V. Sequist et al., "EGFRMutations andALKRearrangements are associated with low response rates to PD-1 pathway blockade in non-small cell lung cancer: a retrospective analysis," Clinical Cancer Research, vol. 22, no. 18, pp. 4585-4593, 2016.

[7] C. K. Lee, J. Man, S. Lord et al., "Clinical and molecular characteristics associated with survival among patients treated with checkpoint inhibitors for advanced non-small cell lung carcinoma: a systematic review and meta-analysis," JAMA Oncology, vol. 4, no. 2, pp. 210-216, 2018.
[8] C. K. Lee, J. Man, S. Lord et al., "Checkpoint Inhibitors in Metastatic EGFR- Mutated Non-Small Cell Lung Cancer -A MetaAnalysis," Journal of Thoracic Oncology, vol. 12, no. 2, pp. 403407, 2017.

[9] S. L. Topalian, J. M. Taube, R. A. Anders, and D. M. Pardoll, "Mechanism-driven biomarkers to guide immune checkpoint blockade in cancer therapy," Nature Reviews Cancer, vol. 16, no. 5, pp. 275-287, 2016.

[10] N. Cheng, W. Cai, S. Ren et al., "Long non-coding RNA UCA1 induces non-T790M acquired resistance to EGFR-TKIs by activating the AKT/mTOR pathway in EGFR-mutant nonsmall cell lung cancer," Oncotarget, vol. 6, no. 27, pp. 2358223593, 2015.

[11] E. Brambilla, G. le Teuff, S. Marguet et al., "Prognostic effect of tumor lymphocytic infiltration in resectable non-small-cell lung cancer," Journal of Clinical Oncology, vol. 34, no. 11, pp. 1223-1230, 2016.

[12] S. I. Grivennikov, F. R. Greten, and M. Karin, "Immunity, inflammation, and cancer," Cell, vol. 140, no. 6, pp. 883-899, 2010.

[13] F. Spill, D. S. Reynolds, R. D. Kamm, and M. H. Zaman, "Impact of the physical microenvironment on tumor progression and metastasis," Current Opinion in Biotechnology, vol. 40, pp. 41-48, 2016.

[14] A. Del Prete, T. Schioppa, L. Tiberio, H. Stabile, and S. Sozzani, "Leukocyte trafficking in tumor microenvironment," Current Opinion in Pharmacology, vol. 35, pp. 40-47, 2017.

[15] F. R. Balkwill, M. Capasso, and T. Hagemann, "The tumor microenvironment at a glance," Journal of Cell Science, vol. 125, no. 23, pp. 5591-5596, 2012.

[16] D. Hanahan and L. M. Coussens, "Accessories to the crime: functions of cells recruited to the tumor microenvironment," Cancer Cell, vol. 21, no. 3, pp. 309-322, 2012.

[17] D. Hanahan and R. A. Weinberg, "Hallmarks of cancer: the next generation," Cell, vol. 144, no. 5, pp. 646-674, 2011.

[18] R. S. Watnick, "The role of the tumor microenvironment in regulating angiogenesis," Cold Spring Harbor Perspectives in Medicine, vol. 2, no. 12, p. a006676, 2012.

[19] H. Angell and J. Galon, "From the immune contexture to the Immunoscore: the role of prognostic and predictive immune markers in cancer," Current Opinion in Immunology, vol. 25, no. 2, pp. 261-267, 2013.

[20] D. M. Pardoll, "The blockade of immune checkpoints in cancer immunotherapy," Cancer, vol. 12, no. 4, pp. 252-264, 2012.

[21] M. Nishino, N. H. Ramaiya, H. Hatabu, and F. S. Hodi, "Monitoring immune-checkpoint blockade: response evaluation and biomarker development," Clinical Oncology, vol. 14, no. 11, pp. 655-668, 2017.

[22] E. K. Nduom, J. Wei, N. K. Yaghi et al., "PD-L1 expression and prognostic impact in glioblastoma," Neuro-Oncology, vol. 18, no. 2, pp. 195-205, 2016.

[23] M. Ji, Y. Liu, Q. Li et al., "PD-1/PD-L1 expression in nonsmall-cell lung cancer and its correlation with EGFR/KRAS mutations," Cancer Biology \& Therapy, vol. 17, no. 4, pp. 407-413, 2016.

[24] A. Lin, T. Wei, H. Meng, P. Luo, and J. Zhang, "Role of the dynamic tumor microenvironment in controversies regarding immune checkpoint inhibitors for the treatment of non-small cell lung cancer (NSCLC) with EGFR mutations," Molecular Cancer, vol. 18, no. 1, p. 139, 2019. 
[25] E. K. Kleczko, J. W. Kwak, E. L. Schenk, and R. A. Nemenoff, "Targeting the complement pathway as a therapeutic strategy in lung cancer," Frontiers in Immunology, vol. 10, p. 954, 2019.

[26] S. Muto, Y. Owada, T. Inoue et al., "Clinical significance of expanded Foxp3+ Helios- regulatory T cells in patients with non-small cell lung cancer," International Journal of Oncology, vol. 47, no. 6, pp. 2082-2090, 2015.

[27] G. Kayser, L. Schulte-Uentrop, W. Sienel et al., "Stromal CD4/CD25 positive T-cells are a strong and independent prognostic factor in non-small cell lung cancer patients, especially with adenocarcinomas," Lung Cancer, vol. 76, no. 3, pp. 445-451, 2012.

[28] K. Bardhan, T. Anagnostou, and V. A. Boussiotis, "The PD1:PD-L1/2 pathway from discovery to clinical implementation," Frontiers in Immunology, vol. 7, 2016.

[29] E. A. Marshall, K. W. Ng, S. H. Y. Kung et al., "Emerging roles of $\mathrm{T}$ helper 17 and regulatory $\mathrm{T}$ cells in lung cancer progression and metastasis," Molecular Cancer, vol. 15, no. 1, p. 67, 2016.

[30] A. P. Ganesan, M. Johansson, B. Ruffell et al., “Tumor-infiltrating regulatory $\mathrm{T}$ cells inhibit endogenous cytotoxic $\mathrm{T}$ cell responses to lung adenocarcinoma," Journal of Immunology, vol. 191, no. 4, pp. 2009-2017, 2013.

[31] W. Wang, P. Hodkinson, F. McLaren et al., "Small cell lung cancer tumour cells induce regulatory $\mathrm{T}$ lymphocytes, and patient survival correlates negatively with FOXP3+ cells in tumour infiltrate," International Journal of Cancer, vol. 131, no. 6, pp. E928-E937, 2012.

[32] N. Erfani, S. M. Mehrabadi, M. A. Ghayumi et al., "Increase of regulatory $\mathrm{T}$ cells in metastatic stage and CTLA-4 over expression in lymphocytes of patients with non-small cell lung cancer (NSCLC)," Lung Cancer, vol. 77, no. 2, pp. 306-311, 2012.

[33] E. C. Halvorsen, S. M. Mahmoud, and K. L. Bennewith, "Emerging roles of regulatory $\mathrm{T}$ cells in tumour progression and metastasis," Cancer Metastasis Reviews, vol. 33, no. 4, pp. 1025-1041, 2014. 